\title{
The tactual horizontal-vertical illusion depends on radial motion of the entire arm
}

\author{
MORTON A. HELLER, JEFFREY A. CALCATERRA, \\ LYNNETTA L. BURSON, and SHAVONDA L. GREEN \\ Winston-Salem State University, Winston-Salem, North Carolina
}

\begin{abstract}
We sought to clarify the causes of the tactual horizontal-vertical illusion, where vertical lines are overestimated as compared with horizontals in $\mathrm{L}$ and inverted-T figures. Experiment 1 did not use $\mathrm{L}$ or inverted-T figures, but examined continuous or bisected horizontal and vertical lines. It was expected that bisected lines would be perceived as shorter than continuous lines, as in the inverted-T figure in the horizontal-vertical illusion. Experiment 1 showed that the illusion could not be explained solely by bisection, since illusory effects were similar for continuous and bisected vertical and horizontal lines. Experiments 2 and 3 showed that the illusory effects were dependent upon stimulus size and scanning strategy. Overestimation of the vertical was minimal or absent for the smallest patterns, where it was proposed that stimuli were explored by finger movement, with flexion at the wrist. Larger stimuli induce whole-arm motions, and illusory effects were found in conditions requiring radial arm motion. The illusion was weakened or eliminated in Experiment 4 when subjects were forced to examine stimuli with finger-and-hand motion alone, that is, their elbows were kept down on the table surface, and they were prevented from making radial arm motions. Whole-arm motion damaged performance and induced perceptual error. The experiments support the hypothesis that overestimation of the vertical in the tactual horizontal-vertical illusion derives from radial scanning by the entire arm.
\end{abstract}

The purpose of the present study was to clarify the causal mechanisms in the tactual horizontal-vertical illusion. In the horizontal-vertical illusion, a vertical line appears to be longer than a horizontal line, even though they are both really the same length (Coren \& Girgus, 1978). In vision, the horizontal-vertical illusion is robust, and people normally overestimate the vertical line component of $L$ and inverted-T figures (Coren \& Girgus, 1978).

The horizontal-vertical illusion has generated considerable interest, and is of clear theoretical significance (see Revesz, 1950). Revesz, for example, claimed that while both vision and touch can "know" space, these two senses are not equally capable of acquiring the same sort of knowledge. Revesz thought that vision was the superior spatial sense and that touch was limited in its ability to perceive precise spatial metrics. Thus, Revesz argued that haptic space does not provide a good understanding of the horizontal or vertical (but see Heller, Calcaterra, Tyler, \& Burson, 1996). Goodnow (1969) thought that the eye and hand might be sensitive to different properties of forms, with the eye being more sensitive to curvature and the hand being more sensitive to orientation. Note, however, that Davidson (1972) reported that blind adults

Preparation of this report and some of the research were supported by NIH Grant 2 SO6 RR-08040. Faith Heller provided helpful comments on an earlier version of this manuscript. H. Dan-Fodio contributed to the design of Experiment 1, and Stevette Barnette and Lisa Tyler assisted with data collection and analyses. Send reprint requests and inquiries to M. A. Heller, Department of Psychology, WinstonSalem State University, Winston-Salem, NC 27110. were better at making judgments of curvature by using touch than were blindfolded sighted adults. Davidson argued that the difference was due to improved perceptual skills in blind subjects.

The basic theoretical issue is whether touch obeys the same perceptual laws as vision. Most researchers have taken this for granted, and have simply investigated visual illusions. For example, Coren and Girgus (1978) devoted one page of their book on visual illusions to the discussion of tactual illusions. They argued that some illusory effects in both vision and touch were explainable in terms of lateral inhibition.

The role of error versus veridical perception is a fundamental perceptual issue (O'Neil, 1958). Some theorists have argued that perception is normally accurate and involves perception of the external world (e.g., Gibson, 1966). It is possible, of course, that similar illusory effects could occur in both vision and touch, but for different reasons. If illusory effects are stronger in one modality, for example in vision, one might wonder whether we need to rethink our understanding of intermodal relations. If, however, the presence of the illusion in touch depends upon the failure to properly or efficiently examine stimuli, other interpretations are possible. Demonstrations of the importance of skill and perceptual activity for veridical perception are consistent with Gibsonian interpretations of perceptual error, that is, "the geometrical illusions are not subjective phenomena as they have always been taken to be, but instead are special cases of the information in variables of optical structure as displayed in drawings" (Gibson, 1966, p. 313). Furthermore, there may be im- 
portant differences between artificial markings or pictures and perception of real-world events (Ittelson, 1996). While Coren and Girgus have claimed that the horizontal-vertical illusion frequently occurs in the natural environment, many of the examples they cite are artificial, as is, for example, the St. Louis Gateway Arch.

An examination of the tactual literature is inconclusive, since while the illusion appears in congenitally blind people (e.g., Bean, 1938; Hatwell, 1960; Heller \& Joyner, 1993), the explanation of the illusion could be different for the senses of vision and touch. It has been proposed that the visual illusion depends upon such factors as the shape of the visual field (Künnapas, 1955), depth cues (Coren \& Girgus, 1978), or retinal meridians (Day \& Avery, 1970). A number of studies suggest that the tactual illusion could be explained in terms of different scanning strategies for horizontal and vertical extents (see Day \& Wong, 1971; Wong, 1977). Day and Wong (1971) proposed that the tactual horizontal-vertical illusion could be explained by radial-tangential scanning effects, where radial movements toward and away from the body were overestimated in comparison with tangential movements. Tangential movements do not converge on the body, whereas radial movements do converge on the body. It should be noted that while tangential movements can be arc-shaped and radial movements are straight, differences between them are negligible in extent at this scale. Furthermore, tangential motions cannot follow a perfect arc while subjects trace a straight line with their fingertips. However, Wong (1977) proposed a scanning rate hypothesis, and argued that radial motions were executed more slowly than tangential movements, and that this rate difference could account for the illusion. On this scanning-rate hypothesis, subjects equate longer scan duration with increases in extent. In addition, the tactual illusion disappears for the L figure when the stimuli are oriented in the frontal plane (as on a CRT display or a wall), and differential scanning is eliminated (Day \& Avery, 1970; Day \& Wong, 1971). Furthermore, if one rotates the inverted-T figure so that the bisected segment of the figure is now the vertical, subjects will still overestimate the vertical (Heller \& Joyner, 1993; Tedford \& Tudor, 1969).

Day and Avery (1970) claimed that the tactual illusory effects were configurational and linked to bisection, since illusory effects were much larger for $T$ than for $L$ figures, and were obtained for the frontally positioned inverted T, but not for the L figure (also see Coren \& Girgus, 1978). This bisection explanation of the illusion suggests that the inverted-T figure really involves two illusory effects, the horizontal-vertical illusion and the divided-space illusion. In the divided-space illusion, the effect of a single division of an extent is to cause a reduction in perceived extent. Thus, the vertical component of the inverted-T figure also bisects the horizontal, and perhaps this division makes the horizontal appear smaller than the vertical. It should be noted that in vision, researchers often orient the stimuli in the frontal plane. The visual illusion is found no matter how the pat- terns are oriented, that is, whether they are in the frontal plane or lying flat on a table surface (as they were in the experiments on touch reported here). When the stimuli are on a table surface, the vertical does not correspond to the gravitational vertical. The stimuli in the present experiments were not oriented in the frontal plane, since that orientation can eliminate or diminish illusory effects in touch and improve perceptual accuracy (Day \& Avery, 1970; Heller, 1992).

Heller and Joyner (1993) suggested that the tactual horizontal-vertical illusion with stimuli lying flat could be influenced by visual experience, since they found a different pattern of results for congenitally blind, late blind, and blindfolded sighted participants. Congenitally blind subjects showed the illusion when given both the $\mathrm{L}$ and the inverted-T figures, and this was consistent with the idea that the illusion was influenced by radial versus tangential scanning effects. The presence of comparable overestimation of verticals with $L$ and inverted- $T$ figures is not explainable in terms of bisection. Furthermore, it was suggested that a number of mechanisms could contribute to the tactual illusion, since the effects were not present in sighted subjects for the smallest stimuli (also see Hatwell, 1960). Heller and Joyner proposed that subjects might engage in different scanning strategies when feeling vertical and horizontal extents, especially those that were larger $(7.5-10.2 \mathrm{~cm})$. Thus, subjects conceivably engaged in whole-arm movements when feeling larger vertical extents, but used finger and wrist motions alone when touching smaller stimuli. When not constrained, subjects typically rested their elbows on the table surface when feeling smaller stimuli by tracing them with the index finger. Illusory effects were clearly larger for the larger stimuli, but the experiments did not specifically manipulate the variable of scanning strategies. In addition, the authors suggested that tactual manipulatory space was larger in the horizontal plane, and thus could act like vision. However, this would not explain the lack of illusory effects for smaller stimuli and the diminished illusion for the $\mathrm{L}$ figure.

Thus, the present experiments were designed to verify these arguments, and to determine if the lack of the illusion for small stimuli could be explained in terms of different scanning strategies for large and small forms and the use of whole-arm movements for larger stimuli. Conceivably, in haptics, poor exploratory strategies or poor touching positions could induce perceptual error and illusory overestimation of verticals, hence the illusion (see Heller, 1992).

Study of the illusion is further complicated by the finding that illusory effects were influenced by the hand used to feel the raised-line patterns (Heller, Joyner, \& Dan-Fodio, 1993). The illusion was found only for inverted-T figures, and no illusion was found for the left thumb. Thus, subjects showed the illusion when using the right thumb to feel patterns, thereby sending input to the left cortex. This suggested that the illusion could be linked to the use of the left hemisphere of the brain, which is specialized for language. Moreover, another ex- 
periment showed that illusory effects were exaggerated by the use of the little finger, but that experiment failed to find laterality effects. Judgments of extent could be linked to hemispace rather than hand, and so Experiment 2 also considered this factor (Bradshaw, Burden, \& Nettleton, 1986; Bradshaw, Nettleton, \& Spehr, 1982). Bradshaw and his colleagues have provided evidence that people may respond differently to stimuli to the left or right of the body midline, and many investigators have failed to properly differentiate the variable of hemispace or spatial location from the influence of laterality and brain specialization. If a subject feels a pattern with the left hand, but the stimulus is in the person's left space, the experimental procedure essentially confounds hand with hemispace.

The present experiments were designed to study the factors contributing to the tactual horizontal-vertical illusion. In Experiment 1, subjects touched continuous or bisected lines to determine if the illusion could be explained in terms of bisection. In Experiment 2, the effects of hemispace, gender, and hand were studied, since prior research had not fully examined all of these variables (Heller \& Joyner, 1993; Heller et al., 1993). Furthermore, observation of subject exploratory behavior in Experiment 1 suggested the possibility of gender differences. In Experiment 3, subjects were required to explore stimuli with their elbows either off of or on the table surface. This experiment was suggested by observation of subjects in prior research (Heller \& Joyner, 1993). It was expected that illusory effects might be induced by larger stimuli in the arms-up group, where it is easier for subjects to scan larger vertical lines with radial whole-arm motions. Subjects in Experiment 4 touched forms either with whole-arm motion or with motion limited to the finger and hand. For one group in Experiment 4, movement strategies were manipulated by using a splint and an elastic bandage to prevent flexion at the wrist or finger to force the subjects to make whole-arm movements. Subjects in a second group were prevented from moving their elbows, and were forced to scan with finger/hand motion alone. It was expected that illusory effects would appear in the groups using whole-arm motion. This was predicted because whole-arm motion was thought to be a likely candidate for the cause of illusory misperception and poor perceptual performance in haptics.

\section{EXPERIMENT 1}

\section{Continuous Versus Bisected Lines}

The purpose of Experiment 1 was to determine if the illusion was explainable in terms of bisection alone. In prior research, the $L$ figure consisted of two equally long lines at a right angle, while the inverted-T figure also comprised two equal lines, with the horizontal line on the bottom. The vertical line thus divided the horizontal line in half, that is, it bisected it. Therefore, one might expect that subjects would underestimate bisected lines, as in the divided horizontal line in the inverted-T figure. According to Coren and Girgus (1978), illusory effects in the inverted-T figure really involve the action of two illusions, the horizontal-vertical illusion and the divided extent illusion, where a single dividing element will lead to underestimation of extent. In all of the inverted-T-like figures of Experiment 1, the vertical and horizontal lines were separated by a $5-\mathrm{cm}$ space. The divided lines were bisected by a 7 -mm-long line at the midpoint. In Experiment 1, L or inverted-T figures were not used; instead, continuous or bisected horizontal and vertical lines were employed. On the notion that underestimation of the horizontal line with respect to the vertical in inverted-T figures derived from bisection, one would expect that subjects would make larger size estimates of continuous lines than they would of bisected lines.

\section{Method}

Subjects. Participants were 24 (11 male, 13 female) righthanded undergraduate volunteers, who received course credit for participation in this study. Handedness was determined by the subject's preferred hand for writing. This experiment did not fully control for hand, since it did not use a multi-item questionnaire. However, no more than 1 or 2 subjects would have been excluded had a formal questionnaire been used. In the present and subsequent experiments, the subjects were recruited on the campus of Winston-Salem State University. Twelve subjects used their left index fingers to feel the stimuli, and 12 used their right index fingers. A separate set of subjects participated in each experiment reported in this manuscript.

Apparatus and Stimuli. Four bisected and four continuous tangible pairs of lines (2.5-, 5.1-, 7.6-, and 10.2-cm lengths) were produced for each orientation (horizontal and vertical) with a raised-line drawing kit. This drawing kit can be obtained from the Swedish agency for special education (SIH, Läromedel, Tomtebodavägen 11, 17164 Solna, Sweden). A durable raised line was produced when the pen was drawn over the textured plastic surface. The thick, black lines were both tangible and visible. The drawing material does not require reversal. If one presses on the surface with a normal ball-point pen, with the plastic over a rubber-surfaced board, a line pops up on the surface. Bisected lines were created by bisecting a continuous line with a perpendicular ( 7 -mm-long) line. Four configurations were drawn on each page; each was like an inverted $\mathrm{T}$, but the patterns included a space of $5 \mathrm{~cm}$ between the vertical line and its horizontal counterpart (see Figure 1). The stimuli were placed at the body midline, flat on a table surface, with the larger $(32-\mathrm{cm})$ side across the width of the table. The vertical lines were on the narrower $(21-\mathrm{cm})$ axis. It is unlikely that this placement could have induced overestimation of the verticals, since subjects were never allowed to feel the entire drawing board surface when they touched individual continuous or bisected pairs of lines.

In the present and subsequent experiments, a Lafayette Instruments (Model 33010, ca. 1985) blindfold with a double layer of plastic was used to block vision. The subjects were unable to see anything through the blindfold. Note that the newer Lafayette blindfolds (as delivered) use a single layer of plastic, and do not completely block vision; they permit vision of "shadows."

Design and Procedure. The experiment was a four-way, between-within design, with hand as a between-groups variable and type of line (continuous or bisected), size, and line orientation (vertical vs. horizontal extents) as within-group variables. The variable of line orientation was a measure of the illusory effect. The subjects felt bisected and continuous lines in different blocks 


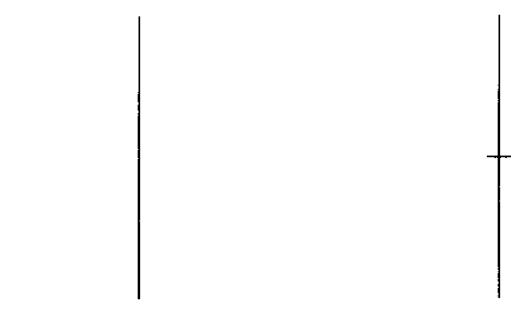

Figure 1. The continuous and bisected lines used in Experiment 1.

of trials, balanced between conditions. Order effects for size were controlled by alternating the order of presentation (either increasing or decreasing size) between stimuli. While it might have been preferable to present the sizes in random order, it was thought that the present procedure would reduce problems associated with subjects' "groping" for starting and ending points of patterns. We wanted to be sure that they completely explored each extent with minimal verbal guidance, and it was thought that large size changes from trial to trial might make this less likely. The subjects felt both the horizontal and the vertical lines of the samesize pair before feeling a line of the next size; they had one trial for each pair of lines, for each of the four sizes of lines.

The subjects used either the left or the right index finger throughout the experiment. They were told to extend the index finger of the hand used to touch the lines, and the stimuli were placed beneath the outstretched finger. Then each subject was instructed to lower his/her finger to feel the stimuli. If the target line was missed, the subject was verbally guided to the raised line. Each subject was told to feel the pair of vertical and horizontal lines with either the left or the right index finger, and then to make judgments about the length of each entire line. Half of the subjects felt the horizontals first, before feeling the verticals, and half of them felt the verticals first. The subjects reported their size estimates in the order in which they felt them, but could always examine a line again if they wished. The subjects reported judgments with the opposite hand, using a pincers posture of the thumb and index finger, like the "C" posture of Van Doren (1995). The experimenter measured this response with a ruler, as if the participant were holding the line between the tips of the fingerprint skin of the two fingers (see Figure 1 in Heller \& Joyner, 1993). All judgments were made parallel to the horizontal line. The subjects were required to feel both parts of the pairs of lines before making each judgment about an individual line. They were told that they could feel the lines for as long as they wished, and time constraints were not imposed in the present or subsequent experiments in this study. While the stimuli were presented at the body midline, the location of the hands making size judgments was not controlled in Experiment 1.

\section{Results}

An analysis of variance (ANOVA) showed that neither the main effect of type of line $(M$ continuous $=7.50 \mathrm{~cm}$, $M$ bisected $=7.36 \mathrm{~cm}$ ) nor its interaction with line orientation was significant (both $F \mathrm{~s}<1$; see Table 1). Stimuli felt with the right hand $(M=7.77 \mathrm{~cm})$ were judged as larger than those felt with the left hand $(M=7.09 \mathrm{~cm})$, but the main effect of hand was also nonsignificant $(F=1.0)$.

Vertical lines $(M=7.69 \mathrm{~cm})$ were generally judged as longer than horizontal lines $(M=7.17 \mathrm{~cm})$. Both size
$[F(3,66)=229.0, p<.001]$ and line orientation $[F(1,22)=$ $25.6, p<.001]$ were significant. The interaction between size and line orientation was also significant $[F(3,66)=$ $5.4, p=.002]$. An analysis of simple effects indicated significant effects of line orientation on the $10.2-\mathrm{cm}$ stimuli $[M$ horizontal $=10.54 \mathrm{~cm}, M$ vertical $=11.61 \mathrm{~cm}$; $F(1,22)=13.3, p=.001]$, on the 7.6 -cm stimuli $[M$ horizontal $=8.25 \mathrm{~cm}, M$ vertical $=8.93 \mathrm{~cm} ; F(1,22)=9.9$, $p=.005]$, and on the $5.4-\mathrm{cm}$ stimuli $[M$ horizontal $=$ $6.21 \mathrm{~cm}, M$ vertical $=6.55 \mathrm{~cm} ; F(1,22)=8.5, p=.008]$, but not on the smallest pattern $(F<1)$. Thus, illusory effects were not found for the $2.5-\mathrm{cm}$ stimuli ( $M$ horizontal $=3.66 \mathrm{~cm}, M$ vertical $=3.69 \mathrm{~cm}$ ). This means that the difference between judgments of the vertical and the horizontal lines increased as the length of the lines increased. None of the other interactions was significant.

\section{Discussion}

Bisection cannot explain the tactual horizontal-vertical illusion, since subjects treated bisected and continuous lines similarly (see Table 1). It is possible that subjects may give illusory responses differently to Ls and inverted Ts because they are letter-like, and we do not usually write horizontal lines that are as large as the verticals in Ls or in Ts. This configurational explanation of the illusion, however, is not consistent with the finding that the verticals were judged as longer than the horizontals, even when the lines were separated.

Although the first experiment did not control for gender, observation of the subjects revealed different behavior patterns that could have been related to gender. Some tall males scanned the stimuli, even the larger stimuli, with finger tracing. This was not possible for many of the females, and it is possible that this different choice of scanning strategy could be related to hand size and not to gender per se. Thus, for both men and women, larger stimuli were likely to induce subjects to lift their forearms off of the table surface and to scan stimuli with whole-arm motions. The strategy of scanning by finger tracing is possible for the smallest stimuli and not the largest stimuli, unless, of course, an individual has very large hands with long fingers.

Table 1

Mean Length Judgments for Type of Line (Bisected or Continuous) as a Function of Hand, Size, and Line Orientation in Experiment $1(\boldsymbol{n}$ per group $=12)$

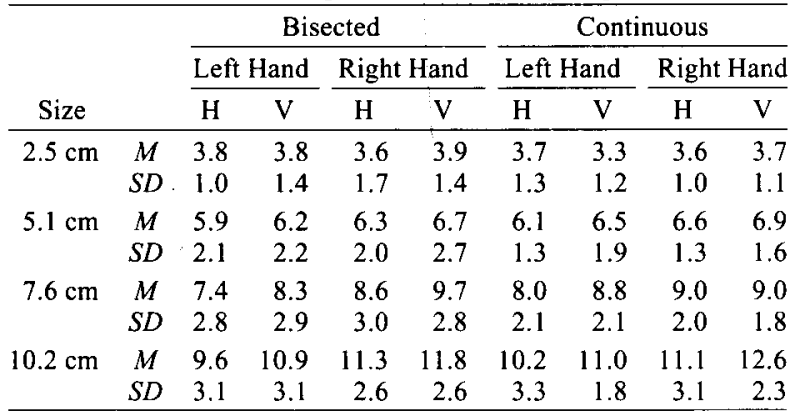

Note- $\mathrm{H}=$ horzontal, $\mathrm{V}=$ vertical. 


\section{EXPERIMENT 2 Effects of Hand and Hemispace}

The next experiment examined the influence of other variables on the tactual horizontal-vertical illusion. Experiment 2 studied hand, hemispace, and gender. Laterality here refers to the effect of hand, while hemispace refers to the left or right region in space "out there" in the world. Thus, if subjects are not constrained, the left hand tends to stray toward the left and the right hand will stray toward the right space. The midline of the body is a reference point for straight ahead.

The purpose of Experiment 2 was to determine if prior demonstrations of the tactual illusion were linked to laterality effects (Heller et al., 1993). In addition, gender was explicitly studied in Experiment 2, since lateralization of the brain has been related to gender (see McKeever, 1991, for a review). Some researchers have claimed that men and women differ in the degree to which the left and right hemispheres are specialized for language skills and spatial relations, with increased specialization for spatial relations in the right hemisphere of men. Prior research in the literature has revealed superior spatial skills in men. Thus, one might expect that men and women might differ in their judgments of extent, and in their susceptibility to illusions when patterns are explored by the left or right hand. On the hypothesis that women may be "less strongly lateralized than men" (see McKeever, 1991, p. 54), one might expect magnified illusory effects in women. Independent groups of men and women examined $\mathrm{L}$ and inverted-T stimuli with their left hands and right hands, giving judgments with the same hand. A "reduced lateralization" view would also predict smaller effects of hand for women.

Experiment 2 was also designed to separate the possible influence of hemispace from laterality effects (see Bradshaw et al., 1986; Bradshaw et al., 1982). In Experiment 2 , hemispace was manipulated by placing the stimuli at the midline or at locations $16.6 \mathrm{~cm}$ to the left or right of the midline. Judgments were made immediately above the stimuli by the same hand. It is possible that judgments of extent could differ for stimuli to the left or right of the body midline. Thus, one can separate the effect of left versus right hand in the left space, at the midline, or in the right space. Use of the left hand in the right space involves crossing the body, as does the use of the right hand in the left space. Moreover, the illusion could be linked to hand, but this may not have been revealed in Experiment 1 due to a lack of control over placement of the hand making judgments. In addition, handedness was self-defined in Experiment 1, and a more comprehensive method was adopted in Experiment 2. Hand was a between-groups variable in Experiment 2 to reduce the number of trials to which each subject would be exposed (repeated measures were taken on hemispace). The use of an independentgroups design was adopted to minimize possible fatigue or learning effects, either of which might have obscured the effect of hand.

\section{Method}

Subjects. The subjects were 32 (16 male, 16 female) righthanded undergraduate volunteers. Participants were considered right-handed in this and subsequent experiments if they responded "right hand" to all questions on a questionnaire (derived from Millar, 1984) asking which hand they used for a number of activities (writing, drawing, throwing a ball, cutting with scissors, using a soup spoon, and brushing teeth). None of the subjects had served in Experiment 1. Data were not collected for the few candidate subjects who were left-handed or were not strongly right-handed. The subjects were restricted to right-handed persons, since they are more strongly lateralized. There were 8 male and 8 female subjects who used their left index fingers to feel the patterns and 8 males and 8 females who used their right index fingers for tactual exploration.

Apparatus and Stimuli. The stimuli were produced with the same raised-line drawing kit and medium-width ball-point pen that were used in Experiment 1. The four Ls and four inverted Ts were drawn with equal-length horizontal and vertical lines of 2.5 , $5.1,7.6$, and $10.2 \mathrm{~cm}$. The patterns were mounted on matte board. Stimuli were positioned with the center of the horizontal line at the body midline and at locations $16.6 \mathrm{~cm}$ to the left and right of the body midline for the stimuli in the left or right hemispace, respectively. It should be noted that the vertical line was always on the left side for the $\mathrm{L}$ shape and in the middle of the pattern for the inverted-T figure. Thus, it is possible, but unlikely, that this difference in placement of the vertical line could have influenced the outcome.

Lester Krueger suggested that the inverted-T figure is different from the $\mathrm{L}$ figure in the location of the vertical line, in addition to the bisection of the horizontal. Thus, this location of the vertical toward the right could alter perceived length. In an attempt to evaluate this possibility, a separate group of subjects $(8$ males and 8 females) made line-length estimates of $L$ and left/right reversed L figures at the body midline. All subjects were right-handed, and all felt the stimuli with the index finger of the right hand. They made size estimates with the left hand at the body midline, with the judgments all parallel to the horizontal line. The experiment was a between- within design, with the between-group factor being gender and with repeated measures taken on figure, size, and line orientation. The only significant main effect was for size $[F(3,42)=$ $222.1, p<.001]$; the other main effects were nonsignificant (all $F \mathrm{~s}<1$ ). Note that the major purpose for this control experiment was to examine the effect of figure, but this variable did not seem to alter perceived size and induce the horizontal-vertical illusion $(M \mathrm{~L}$ horizontal $=7.4, M \mathrm{~L}$ vertical $=7.58 ; M$ reversed $\mathrm{L}$ horizontal $=7.35, M$ reversed $\mathrm{L}$ vertical $=7.35)$. The interaction between gender $(M$ males $=7.67 \mathrm{~cm} ; M$ females $=7.12 \mathrm{~cm})$ and line orientation $(M$ males horizontal $=7.47 \mathrm{~cm}, M$ males vertical $=$ $7.87 \mathrm{~cm} ; M$ females horizontal $=7.29 \mathrm{~cm}, M$ females vertical $=$ $7.06 \mathrm{~cm}$ ) was nonsignificant $[F(1,14)=2.8, p>.10]$, as were all of the other interaction effects (all $p s>30$ ). This means that any differences between the $L$ and inverted- $T$ figures cannot be explained merely in terms of the location of the vertical line.

Design and Procedure. The experiment was a six-way, betweenwithin design, with between-groups factors of hand and gender $(2$ $\times 2 \times 3 \times 4 \times 2 \times 2$, hand $\times$ gender $\times$ hemispace $\times$ size $\times$ figure $\times$ orientation). Repeated measures were taken on hemispace (left hemispace, body midline, and right hemispace), size, figure ( $\mathrm{L}$ and inverted $\mathrm{T}$ ), and line orientation (vertical or horizontal lines). The sequence of spatial locations was balanced across participants, each sequence appearing at least once. The sequence of patterns ( $\mathrm{L}$ and inverted $\mathrm{T}$ ) was balanced within each spatial location and across conditions. Order effects for size were controlled by alternating the order of series type (either ascending first vs. descending first) between patterns. Half of the subjects judged the verticals first, and half of them judged the horizontal 
extents first. The subjects had one trial in which they judged the extent of the horizontal and vertical lines, at each level of hemispace, size, and figure.

The subjects were blindfolded throughout the experiment. They were instructed to feel the entire pattern with either the left or the right index finger, then make judgments about the length of each component with the same hand. Judgments were given in the same direction as the lines, and just above each pattern. It was important for the subjects to use the same hand, since use of the opposite hand for judgments would have made it difficult to control for hemispace, a major purpose of the experiment. The two hands could have gotten in the way of each other and the subjects would not have been able to make their judgments at the same location at which they felt the stimuli. Use of the same hand for exploration and judgments was designed to yield more precise control over both hand and hemispace.

\section{Results}

A between-within ANOVA revealed the presence of the illusion, and a relationship between hemispace and hand (see Table 2). There were significant main effects of size $[F(3,84)=719.0, p<.001]$, line orientation $[F(1,28)=12.3, p=.002]$, and figure $[F(1,28)=5.1, p=$ $.031]$. The effect of line orientation involved illusory overestimations of the verticals $(M=7.53 \mathrm{~cm})$ with respect to horizontal lines $(M=7.11 \mathrm{~cm})$. There were no significant main effects of hand $(M$ left $=7.18 \mathrm{~cm}$, $M$ right $=7.46 \mathrm{~cm} ; F<1)$ or hemispace $[M]$ eft $=7.43 \mathrm{~cm}$, $M$ midline $=7.35 \mathrm{~cm}, M$ right $=7.18 \mathrm{~cm} ; F(2,56)=1.1$, $p>.331]$. Note that the illusion was found, even though the size judgments were made with the hand parallel to the lines being judged. This is important, since Marchetti and Lederman (1983) have reported diminished illusory effects when responses were in the same orientation as the rods they explored. One reviewer suggested that the fact that this procedure did not completely block the illusion indicates that it was not caused by movementindependent anisotropies of haptic space.

While neither hand nor hemispace had a significant effect on length judgments, the interaction between the two variables was significant $[F(2,56)=3.8, p=.03]$. An analysis of simple effects showed a significant effect of hemispace on judgments given with the left hand $[F(2,56)=$ $3.9, p=.026]$ but not on those given with the right hand $(F=1.0)$. Left-hand judgments at the body midline $(M=$ $7.06 \mathrm{~cm})$ and in the right hemispace $(M=6.93 \mathrm{~cm})$ were smaller than the judgments in the left hemispace $(M=$ $7.56 \mathrm{~cm}$ ). Judgments given with the right hand were fairly constant across hemispace $(M$ left $=7.30 \mathrm{~cm}, M$ midline $=7.64 \mathrm{~cm}, M$ right $=7.43 \mathrm{~cm}$; see Table 2). The interaction between hand, hemispace, and orientation was nonsignificant $(F=1)$, as was the interaction between hemispace and the presence of the illusion, that is, line orientation $(F<1)$.

Although the main effect of line orientation was highly significant, the interaction between hand and line orientation was also significant $[F(1,28)=11.3, p=.002]$. An analysis of simple effects indicated a significant effect of line orientation on judgments made with the left hand $[F(1,28)=23.6, p<.001]$ but not on those made with the right hand $(F<1)$. The illusion was linked to use of the left hand, and thus the right hemisphere of the brain. Measured with the left hand, the vertical lines $(M=$ $7.60 \mathrm{~cm}$ ) were judged as longer than the horizontal lines $(M=6.77 \mathrm{~cm})$. This was not the case with the right hand ( $M$ horizontal $=7.45 \mathrm{~cm}, M$ vertical $=7.46 \mathrm{~cm})$.

Line orientation also interacted with size $[F(3,84)=$ $8.7, p<.001]$. An analysis of simple effects showed a significant effect of line orientation on the $5.1-\mathrm{cm}[M$ horizontal $=5.99 \mathrm{~cm}, M$ vertical $=6.30 \mathrm{~cm} ; F(1,28)=6.8, p=$ $.014], 7.6-\mathrm{cm}(M$ horizontal $=8.49 \mathrm{~cm}, M$ vertical $=$ $8.90 \mathrm{~cm} ; F(1,28)=5.1, p<.033]$, and $10.2-\mathrm{cm}(M$ horizontal $=10.29 \mathrm{~cm}, M$ vertical $=11.18 \mathrm{~cm} ; F(1,28)=19.1$, $p<.001]$ patterns, but not on the $2.5-\mathrm{cm}[M$ horizontal $=$ $3.66 \mathrm{~cm}, M$ vertical $=3.76 \mathrm{~cm} ; F<1]$ pattern. The difference between vertical and horizontal length judgments increased as the size of the figures increased. There was minimal illusory overestimation of verticals of the $2.5-\mathrm{cm}$ patterns.

The effect of gender, shown by smaller judgments by males $(M$ males $=6.87 \mathrm{~cm}, M$ females $=7.77 \mathrm{~cm})$, was marginally significant $[F(1,28)=3.1, p=.087]$. The threeway interaction between gender, hemispace, and figure was significant $[F(2,56)=3.4, p<.05]$. For the purpose of clarification of this triple interaction, the data for males and females in Experiment 2 were considered as separate experiments, and were reanalyzed. An ANOVA on the female data considered separately showed a highly significant effect of stimulus size $[F(3,42)=445.0$, $p<.001]$, but the main effects of hand and hemispace were nonsignificant (both $F_{\mathrm{S}}<1$ ), as was the effect of line orientation $[M$ horizontal $=7.61 \mathrm{~cm}, M$ vertical $=$ $7.94 \mathrm{~cm} ; F(1,14)=2.93, p>.11]$. The interaction between hemispace and figure was nonsignificant $(F<1)$.

A separate ANOVA on the data for the males showed nonsignificant effects of hand $(F<1)$ and hemispace $[F(2,28)=1.14, p=.33]$. The effect of line orientation $(M$ horizontal $=6.61 \mathrm{~cm}, M$ vertical $=7.13 \mathrm{~cm}$ ) was significant $[F(1,14)=12.45, p=.003]$ as was the effect of size $[F(3,42)=293.33, p<.001]$. The effect of figure was marginally significant $[F(1,14)=3.10, p=.10]$. However, there was a significant interaction between hemispace and figure $[F(2,28)=4.28, p=.024]$. The simple effect of hemispace was nonsignificant for the $\mathrm{L}$ figure $(F<1)$ but marginally significant for the inverted-T figure $[F(2,28)=$ $3.33, p=.051]$. This means that males showed similar size judgments across space for the $L$ figure. However, they treated the figures differently at the midline $(M \mathrm{~L}=7.1 \mathrm{~cm}$, $M \mathrm{~T}=6.49 \mathrm{~cm})$ and the right space $(M \mathrm{~L}=7.04 \mathrm{~cm}, M \mathrm{~T}=$ $6.49 \mathrm{~cm})$, but treated them alike in the left hemispace $(M$ $\mathrm{L}=6.98 \mathrm{~cm}, M \mathrm{~T}=7.15 \mathrm{~cm}$ ). Males showed a nonsignificant simple effect of figure in the left hemispace $(F<1)$ but a significant effect at the midline $[F(1,14)=5.51, p=$ $.034]$ and in the right hemispace $[F(1,14)=4.72, p<.05]$.

\section{Discussion}

It is unlikely that the obtained results reveal basic differences in lateralization for males and females. A lateralization explanation of the results of Experiment 2 would predict that the illusion should be linked to the use 
Table 2

Mean Length Judgments as a Function of Gender, Figure, Hand, Hemispace, Size, and Line Orientation in Experiment 2

\begin{tabular}{|c|c|c|c|c|c|c|c|c|c|c|c|c|c|}
\hline \multirow[b]{3}{*}{ Size } & & \multicolumn{6}{|c|}{ Left Hand } & \multicolumn{6}{|c|}{ Right Hand } \\
\hline & & \multicolumn{2}{|c|}{ Left } & \multicolumn{2}{|c|}{ Midline } & \multicolumn{2}{|c|}{ Right } & \multicolumn{2}{|c|}{ Left } & \multicolumn{2}{|c|}{ Midline } & \multicolumn{2}{|c|}{ Right } \\
\hline & & $\mathrm{H}$ & $\mathrm{V}$ & $\mathrm{H}$ & $\mathrm{V}$ & $\mathrm{H}$ & $\mathrm{V}$ & $\mathrm{H}$ & $\mathrm{V}$ & $\mathbf{H}$ & $\mathrm{V}$ & $\mathrm{H}$ & $\mathrm{V}$ \\
\hline \multicolumn{14}{|c|}{ Males $(n=16)$ : Inverted T-Figure } \\
\hline \multirow[t]{2}{*}{$2.5 \mathrm{~cm}$} & $M$ & 3.6 & 3.3 & 3.1 & 3.1 & 2.8 & 3.3 & 3.9 & 3.6 & 3.5 & 3.4 & 3.3 & 3.2 \\
\hline & $S D$ & 1.5 & 1.7 & .8 & 1.1 & 1.1 & .9 & 1.8 & 1.3 & .7 & 1.2 & .7 & 1.0 \\
\hline \multirow[t]{2}{*}{$5.1 \mathrm{~cm}$} & $M$ & 5.7 & 6.5 & 4.8 & 5.3 & 4.8 & 5.4 & 5.8 & 6.3 & 5.9 & 5.4 & 5.5 & 5.2 \\
\hline & $S D$ & 2.1 & 2.6 & 1.4 & 1.6 & 1.2 & 1.7 & 1.7 & 1.8 & 1.7 & 1.9 & 1.3 & 1.0 \\
\hline \multirow[t]{2}{*}{$7.6 \mathrm{~cm}$} & $M$ & 8.6 & 9.3 & 7.5 & 7.7 & 7.7 & 7.9 & 8.2 & 8.7 & 8.3 & 8.0 & 7.8 & 7.4 \\
\hline & $S D$ & 2.6 & 3.0 & 2.0 & 2.9 & 2.4 & 2.4 & 2.1 & 2.4 & 2.3 & 1.6 & 2.4 & 2.0 \\
\hline \multirow[t]{2}{*}{$10.2 \mathrm{~cm}$} & $M$ & 9.5 & 11.6 & 8.6 & 10.8 & 9.3 & 9.9 & 9.3 & 10.7 & 8.7 & 9.8 & 9.9 & 10.5 \\
\hline & $S D$ & 2.5 & 2.6 & 2.3 & 3.0 & 2.3 & 3.2 & 1.6 & 3.0 & 2.0 & 2.6 & 2.3 & 2.5 \\
\hline \multicolumn{14}{|c|}{ Males: L Figure } \\
\hline \multirow[t]{2}{*}{$2.5 \mathrm{~cm}$} & $M$ & 3.6 & 3.8 & 3.0 & 3.8 & 3.0 & 4.0 & 3.4 & 3.6 & 3.7 & 3.3 & 3.8 & 3.4 \\
\hline & $S D$ & 1.4 & 1.6 & 1.5 & 1.5 & 1.0 & 1.4 & 1.2 & .8 & 1.1 & .9 & 1.1 & 1.0 \\
\hline \multirow[t]{2}{*}{$5.1 \mathrm{~cm}$} & $M$ & 6.0 & 6.4 & 4.9 & 6.0 & 5.2 & 6.6 & 5.5 & 5.7 & 6.4 & 6.6 & 6.1 & 5.6 \\
\hline & $S D$ & 2.1 & 2.4 & 1.7 & 2.1 & 2.2 & 2.7 & 1.2 & .9 & 1.4 & 2.0 & 1.2 & 1.0 \\
\hline \multirow[t]{2}{*}{$7.6 \mathrm{~cm}$} & $M$ & 8.1 & 9.1 & 7.4 & 8.4 & 7.1 & 8.7 & 7.7 & 7.8 & 8.6 & 9.1 & 8.6 & 8.2 \\
\hline & $S D$ & 2.9 & 3.8 & 2.0 & 2.5 & 1.6 & 2.1 & 1.8 & 1.1 & 1.8 & 1.2 & 2.2 & .9 \\
\hline \multirow[t]{2}{*}{$10.2 \mathrm{~cm}$} & $M$ & 9.3 & 11.6 & 9.6 & 11.0 & 10.3 & 11.6 & 9.8 & 10.5 & 9.8 & 11.2 & 10.3 & 10.2 \\
\hline & $S D$ & 3.4 & 3.5 & 1.9 & 3.8 & 2.0 & 2.4 & 2.1 & 1.6 & 1.9 & 2.0 & 1.7 & 1.9 \\
\hline \multicolumn{14}{|c|}{ Females $(n=16)$ : Inverted-T Figure } \\
\hline \multirow[t]{2}{*}{$2.5 \mathrm{~cm}$} & $M$ & 4.0 & 3.7 & 3.8 & 3.9 & 3.4 & 3.4 & 3.8 & 3.8 & 4.7 & 4.2 & 4.6 & 4.2 \\
\hline & $S D$ & 1.1 & 1.6 & 1.4 & .9 & 1.5 & 1.2 & 1.4 & 1.6 & 1.5 & 1.5 & 1.4 & 1.2 \\
\hline \multirow{2}{*}{$5.1 \mathrm{~cm}$} & $M$ & 6.5 & 6.9 & 5.9 & 6.6 & 5.3 & 5.8 & 6.4 & 6.5 & 6.9 & 7.4 & 6.5 & 6.9 \\
\hline & $S D$ & 1.8 & 1.3 & 2.1 & 1.6 & 1.8 & 1.7 & 2.1 & 2.1 & 2.1 & 1.5 & 1.9 & 1.3 \\
\hline \multirow[t]{2}{*}{$7.6 \mathrm{~cm}$} & $M$ & 9.2 & 9.2 & 8.2 & 9.3 & 7.8 & 9.0 & 9.3 & 9.2 & 9.9 & 9.9 & 9.6 & 9.7 \\
\hline & $S D$ & 1.9 & 2.2 & 2.6 & 2.8 & 1.8 & 2.3 & 2.7 & 2.1 & 3.0 & 2.5 & 3.2 & 3.1 \\
\hline $10.2 \mathrm{~cm}$ & $M$ & 10.4 & 11.3 & 10.4 & 11.7 & 9.1 & 10.9 & 11.1 & 11.0 & 11.9 & 11.8 & 12.2 & 11.4 \\
\hline & $S D$ & 1.9 & 1.5 & 2.9 & 1.9 & 1.5 & 1.8 & 2.4 & 2.4 & 2.3 & 2.2 & 2.7 & 1.6 \\
\hline & & & & & Fema & ales: L & Figur & & & & & & \\
\hline $2.5 \mathrm{~cm}$ & $M$ & 3.6 & 4.4 & 4.0 & 4.9 & 3.3 & 3.9 & 4.2 & 3.9 & 4.0 & 4.2 & 4.0 & 4.0 \\
\hline & $S D$ & 1.5 & 1.5 & 1.9 & 1.5 & 1.4 & 1.3 & .9 & .6 & 1.5 & 1.3 & 1.1 & .9 \\
\hline $5.1 \mathrm{~cm}$ & $M$ & 6.8 & 7.2 & 5.9 & 6.8 & 6.3 & 6.0 & 6.7 & 6.4 & 7.4 & 7.1 & 6.7 & 6.5 \\
\hline & $S D$ & 1.9 & 2.0 & 2.1 & 1.8 & 1.7 & 1.4 & 1.5 & 1.7 & 2.3 & 1.5 & 1.7 & 1.7 \\
\hline $7.6 \mathrm{~cm}$ & $M$ & 9.3 & 10.2 & 8.1 & 9.2 & 8.1 & 9.4 & 8.9 & 9.4 & 9.8 & 9.8 & 9.8 & 9.2 \\
\hline & $S D$ & 3.1 & 2.8 & 3.0 & 1.7 & 1.4 & 2.0 & 1.9 & 1.6 & 2.5 & 1.5 & 2.7 & 1.1 \\
\hline $10.2 \mathrm{~cm}$ & $M$ & 11.3 & 12.2 & 10.3 & 11.9 & 10.5 & 12.2 & 11.9 & 10.9 & 11.8 & 11.8 & 11.7 & 12.0 \\
\hline & $S D$ & 2.5 & 2.4 & 3.3 & 1.8 & 2.0 & 1.7 & 2.5 & 2.4 & 1.8 & 1.8 & 2.0 & 2.3 \\
\hline
\end{tabular}

Note- $\mathrm{H}=$ horizontal, $\mathrm{V}=$ vertical.

of the left hemisphere of the brain, and one would certainly expect greater differences between the hands for males than for females (see Bryden \& Steenhuis, 1991). This analysis assumes that the right hemisphere is better at spatial tasks, and thus perceptual errors (i.e., illusions) may be induced via the involvement of the left hemisphere. However, the data indicated that the left hand and right hemisphere showed the stronger illusion, with a similar involvement of the left hand for both men and women.

In addition, the role of the left hand in the tactual illusion may derive from motor control problems for righthanded subjects. Illusory overestimation of verticals may become more likely as tactual exploration becomes less skilled. Moreover, subjects may simply be less accurate when making judgments of extent when monitoring motor activity in the left hand. Scan-rate control may be less precise with the use of the left hand for scanning, and this could explain some of the data of Experiment 2. Note that Wong (1977) has claimed that radial motions are executed more slowly than tangential motions and has related scanning rate to the presence of the illusion.

The effects of gender and hand were small in the present experiments, and may be explicable in terms of some factor other than lateralization, perhaps spatial compatibility. Note that the illusion was somewhat stronger in males than in females. The arms and hands of males are probably less flexible than those of females, and this may have served to reduce the size of the judgments of the males at the midline and the right hemispace. This size reduction may have been more likely in some individuals when their left hands crossed the body midline. Also, gender may be confounded with body size. The mean data for the females in this experiment were altered by the judgments of a couple of very tall women who gave unusually large judgments. The data of the present experiments are not consistent with simplistic explanations in terms of cerebral lateralization. Nonetheless, research in this area should control for these variables. 
One reviewer wondered about the range of sizes chosen for this experiment, and suggested that range limitations for the largest stimuli and the pincers method could affect the magnitude of the illusion. This assumes that subjects may have had some difficulty with the largest stimuli because they could not open their fingers widely enough. It is also possible that subjects hesitated to give extreme judgments. However, the subjects generally gave overestimations of size in the present study. It is possible that this overestimation represents a form of subject bias, but it could also derive from lack of familiarity with the use of touch for size estimation.

Range effects have been reported (Chan, Carello, \& Turvey, 1990), and they can restrict size judgments given standards as large as $13 \mathrm{~cm}$. Although the overestimations in the present experiments could be related to the response measure, Chan et al. reported little underestimation, even of larger $(10 \mathrm{~cm})$ patterns using a similar response measure. They reported that haptically perceived width was equivalent to visually perceived width. However, they suggested that some compression (underestimation) could occur when standards were larger than $10 \mathrm{~cm}$. However, this is unlikely to have occurred in our Experiments 1 and 2 , since subjects often overestimated the sizes of the largest stimuli (see Table 2). Furthermore, this cannot explain the lack of an effect of line orientation with the smallest patterns, a finding that is consistent with earlier reports in the literature (e.g., Hatwell, 1960). Other researchers have previously reported overestimations of tactually experienced extent (Balakrishnan, Klatzky, Loomis, \& Lederman, 1989). Balakrishnan et al. reported that overestimation was far more common with slower rates of exploration. Perhaps our subjects scanned relatively slowly because of their unfamiliarity with the task.

There is an alternative explanation of the obtained overestimation that should be considered. The horizontalvertical illusion may derive from radial scanning of the entire arm. Larger stimuli and vertical extents prompt this sort of radial arm motion, where flexing occurs at the elbow and shoulder. This possibility was examined more explicitly in Experiments 3 and 4.

\section{EXPERIMENT 3 Elbows On or Off of the Table Surface}

A number of variables that influence the tactual horizontal-vertical illusion were identified in Experiments 1 and 2. Experiment 1 showed that the illusion was not explainable in terms of bisection alone, and both Experiment 1 and Experiment 2 showed robust effects of stimulus size. The next experiment explored the possibility that, in free-scanning conditions, smaller stimuli and larger patterns induce different scanning strategies.

This experiment evaluated the effect of elevating the arm off of the table surface. Under natural, uncontrolled circumstances, subjects were observed adopting different exploratory strategies when confronted by large and small configurations. Smaller stimuli could be scanned with finger and wrist motions, with the forearm resting on the horizontal tabletop. Larger stimuli typically required the use of radial scanning of verticals, using a whole-arm motion. In the case of larger stimuli, subjects appeared to lift their arms off of the table and to move their arms with flexion at the elbow and shoulder. Large, whole-arm motions are clumsier than finger motions, and it was considered probable that this could induce perceptual errors and illusory overestimation of verticals.

The purpose of Experiment 3 was to determine if this differential scanning pattern could explain the emergence of illusory effects. One group of subjects was told to feel the patterns with their elbows down and immobile on the table. The subjects in a second group were always required to elevate their arms, and keep their elbows off the table. It was expected that the illusion would be larger in the group of subjects required to keep their elbows off of the table.

\section{Method}

Subjects. There were 20 right-handed (as defined in Experiment 2) subjects in the experiment. Half of the subjects in the elbows-up group $(n=10)$ and the elbows-down group $(n=10)$ were males and half were females. None of the subjects had served in any of the preceding experiments.

Apparatus and Stimuli. The stimuli were like those of Experiment 2, but were placed at the body midline.

Design and Procedure. The experiment had a between-within design, with independent groups of subjects in the elbows-up group and in the elbows-down group. Repeated measures were taken on figure ( $\mathrm{L}$ or inverted $\mathrm{T})$, size $(2.5-, 5.1-, 7.6-$, and $10.2-\mathrm{cm}$ lengths), line orientation (horizontal or vertical judgments), and hand (left vs. right). As in Experiment 2, the subjects made a single pair of judgments at each level of figure and size. Line-length judgments were made with the opposite hand and a pincers posture in the horizontal plane. In the elbows-up group, the subjects were told that they should not rest their arms on the table while feeling patterns and making judgments. The subjects in the elbows-down group were told to rest their elbows on a $3.2-\mathrm{cm}$ square of 6-mm-thick soft foam-insulation tape placed on the table surface. These subjects were told that they should not move their elbows off of the foam tape during the experiment. Tape/elbow placement was to the right or left of the stimuli for the subjects, and placement was varied for each individual to ensure that all subjects would be able to fully examine each pattern with their elbows immobile on the tape. The proper location of the stimuli on the table was derived from prior examination of a few individuals with long arms and other individuals with short arms. These individuals were asked to move their arms around the table surface, and this allowed for the determination of an appropriate placement for the stimuli. The stimuli were presented within a 10.2-cm-diam circle that was drawn on the table surface (for the benefit of the experimenter), within reach of subjects with long or short arms.

\section{Results}

Table 3 summarizes the results of the experiment and shows mean length estimates for each condition. The data were analyzed using a $2 \times 2 \times 2 \times 4 \times 2$ ANOVA (elbow placement $\times$ hand $\times$ figure $\times$ size $\times$ line orientation). The ANOVA showed significant main effects of stimulus size $[F(3,54)=333.5, p<.001]$ and line orientation $[F(1,18)=11.0, p<.01]$, showing an illusion. 
Table 3

Mean Length Judgments as a Function of Arm Movement (Elbows-Up or Elbows-Down), Hand, Figure, Size, and Orientation in Experiment 3

\begin{tabular}{|c|c|c|c|c|c|c|c|c|c|}
\hline \multirow[b]{3}{*}{ Size } & & \multicolumn{4}{|c|}{ Elbows-Up } & \multicolumn{4}{|c|}{ Elbows-Down } \\
\hline & & \multicolumn{2}{|c|}{ Left Hand } & \multicolumn{2}{|c|}{ Right Hand } & \multicolumn{2}{|c|}{ Left Hand } & \multicolumn{2}{|c|}{ Right Hand } \\
\hline & & $\mathrm{H}$ & $\mathrm{V}$ & $\mathrm{H}$ & $\mathrm{V}$ & $\mathrm{H}$ & $\mathrm{V}$ & $\mathrm{H}$ & $\mathrm{V}$ \\
\hline \multicolumn{10}{|c|}{ Inverted-T Figure } \\
\hline \multirow[t]{2}{*}{$2.5 \mathrm{~cm}$} & $M$ & 3.2 & 3.1 & 2.9 & 3.0 & 3.3 & 2.7 & 4.1 & 3.8 \\
\hline & $S D$ & .8 & .8 & 1.2 & 1.0 & 1.2 & 1.0 & 1.6 & 1.6 \\
\hline \multirow[t]{2}{*}{$5.1 \mathrm{~cm}$} & $M$ & 4.9 & 5.2 & 5.5 & 6.2 & 5.7 & 5.0 & 6.1 & 6.0 \\
\hline & $S D$ & 1.2 & 1.2 & 1.8 & 1.9 & 1.3 & 1.3 & 1.3 & 1.4 \\
\hline \multirow[t]{2}{*}{$7.6 \mathrm{~cm}$} & $M$ & 6.3 & 7.2 & 7.3 & 8.4 & 7.8 & 8.1 & 9.0 & 8.6 \\
\hline & $S D$ & 1.4 & 1.7 & 1.9 & 2.7 & 1.8 & 2.1 & 2.3 & 1.7 \\
\hline \multirow[t]{2}{*}{$10.2 \mathrm{~cm}$} & $M$ & 7.9 & 10.3 & 9.5 & 11.5 & 10.7 & 11.5 & 11.2 & 11.2 \\
\hline & $S D$ & 1.4 & 1.8 & 1.7 & 2.1 & 1.8 & 2.3 & 2.1 & 2.5 \\
\hline \multicolumn{10}{|c|}{ L Figure } \\
\hline \multirow[t]{2}{*}{$2.5 \mathrm{~cm}$} & $M$ & 3.2 & 3.4 & 2.7 & 3.0 & 2.6 & 2.6 & 3.5 & 3.4 \\
\hline & $S D$ & 1.1 & .9 & 1.1 & 1.0 & .7 & .8 & 1.2 & 1.2 \\
\hline \multirow[t]{2}{*}{$5.1 \mathrm{~cm}$} & $M$ & 5.3 & 5.8 & 4.5 & 5.0 & 5.4 & 5.4 & 6.4 & 6.2 \\
\hline & $S D$ & I. I & 1.1 & 1.2 & 1.3 & 1.7 & 1.5 & 9 & 1.2 \\
\hline \multirow[t]{2}{*}{$7.6 \mathrm{~cm}$} & $M$ & 7.3 & 8.0 & 6.9 & 8.0 & 8.5 & 7.5 & 8.0 & 8.5 \\
\hline & $S D$ & 1.0 & 1.6 & 2.1 & 2.2 & 2.3 & 1.6 & 1.9 & 1.6 \\
\hline \multirow[t]{2}{*}{$10.2 \mathrm{~cm}$} & $M$ & 8.8 & 9.9 & 8.8 & 10.7 & 11.4 & 11.3 & 10.8 & 11.1 \\
\hline & $S D$ & 2.3 & 2.8 & 2.1 & 2.8 & 1.6 & 1.9 & 2.5 & 1.9 \\
\hline
\end{tabular}

Note-Elbows-up and elbows-down groups had 10 subjects each. $\mathrm{H}=$ horizontal, $\mathrm{V}=$ vertical.

The other main effects were nonsignificant, with the effect of elbow placement ( $M$ elbows up $=6.36 \mathrm{~cm}, M$ elbows down $=7.09 \mathrm{~cm}$ ) failing to reach significance $[F(1,18)=2.6, p>.10]$.

The presence of the illusion was dependent upon elbow placement, since elbow placement significantly interacted with line orientation $[F(1,18)=17.5, p<.001]$. Table 3 shows that the illusion was diminished or absent when subjects kept their elbows down and immobile on the table surface. This means that illusory effects were dependent upon subjects' keeping their elbows off of the table surface. The simple effect of line orientation was significant for the elbows-up group [ $M$ horizontal $=$ $5.93 \mathrm{~cm}, M$ vertical $=6.78 \mathrm{~cm} ; F(1,28)=28.2, p<.001]$, but the effect of line orientation was nonsignificant in the elbows-down group $(F<1 ; M$ horizontal $=7.14 \mathrm{~cm}$, $M$ vertical $=7.04 \mathrm{~cm}$ )

The effect of line orientation also interacted significantly with stimulus size $[F(3,54)=10.4, p<.001]$. There was also a significant interaction between line orientation, stimulus size, and elbow placement $[F(3,54)=$ $3.3, p=.026]$. The two-way interaction between the effect of line orientation and elbow placement was even more evident for the larger, 7.6- and 10.2-cm stimuli.

A separate analysis for the elbows-down group yielded a nonsignificant interaction between line orientation and size $(F<1)$. For the elbows-down subjects, the illusory effect was absent for $2.5-\mathrm{cm}$ stimuli $(M$ horizontal $=$ $3.35 \mathrm{~cm}, M$ vertical $=3.1 \mathrm{~cm}), 5.4-\mathrm{cm}$ stimuli $(M$ horizontal $=5.87 \mathrm{~cm}, M$ vertical $=5.63 \mathrm{~cm}$ ), and $7.6-\mathrm{cm} \mathrm{stim-}$ uli $(M$ horizontal $=8.31 \mathrm{~cm}, M$ vertical $=8.18 \mathrm{~cm})$, and minimal for the $10.2-\mathrm{cm}$ stimuli $(M$ horizontal $=11.04 \mathrm{~cm}$, $M$ vertical $=11.26 \mathrm{~cm})$. However, an analysis of the elbows-up group showed that line orientation interacted significantly with size $[F(3,27)=14.6, p<.001]$.

An examination of the simple effect of the interaction between line orientation and size for the elbows-up group showed that the effect of line orientation was highly significant for $10.2-\mathrm{cm}$ stimuli $(M$ horizontal $=8.75 \mathrm{~cm}$, $M$ vertical $=10.60 \mathrm{~cm}), 7.6-\mathrm{cm}$ stimuli $(M$ horizontal $=$ $6.96 \mathrm{~cm}, M$ vertical $=7.89 \mathrm{~cm})$, and $5.1-\mathrm{cm}$ stimuli $(M$ horizontal $=5.03 \mathrm{~cm}, M$ vertical $=5.53 \mathrm{~cm})($ all $p \mathrm{~s}<.01)$, but the effect of line orientation was nonsignificant for the 2.5 -cm stimuli $(F<1 ; M$ horizontal $=3.00 \mathrm{~cm}, M$ vertical $=3.11 \mathrm{~cm}$ ).

The interaction between hand and size was nonsignificant, as was the interaction between hand and elbow placement (both $F \mathrm{~s}<1$ ). However, the effect of hand interacted with stimulus size and elbow placement $[F(3,54)=4.1$, $p<.01]$. This interaction was shown by smaller judgments by the left hand for the larger $7.6-$ and $10.2-\mathrm{cm}$ stimuli in the elbows-up group (see Table 3 ).

\section{Discussion}

The results of Experiment 3 were consistent with the idea that the horizontal-vertical illusion derived from the subjects' adopting different scanning strategies when feeling large and small forms and for vertical and horizontal extents. Thus, given free exploration, the subjects were likely to engage in radial scanning movements when examining larger forms, but could use finger and hand/wrist motion for smaller stimuli. This could explain the absence of the illusion for $2.5-\mathrm{cm}$ stimuli (also reported by Hatwell, 1960). Whole-arm scanning resulted in lower perceptual accuracy and hurt performance. Note that whole-arm scanning induced subjects to actually underestimate the horizontal extents of the larger (7.6- and $10.2-\mathrm{cm}$ ) inverted-T figures.

Perhaps the experimental paradigm would have been more sensitive to the effect of hand, if the subjects had been required to use the same hand for exploration and size judgments. However, this was not possible in Experiment 4, and Experiment 3 was designed as a preliminary test of the importance of whole-arm movement that was examined further in Experiment 4 . It was also thought that it would be difficult to control movement if subjects used the same hand for feeling the lines and making size estimates in Experiment 3, since there is a normal tendency to engage in movement while feeling stimuli. It would probably have been very difficult to eliminate this tendency in the elbows-down group if the subjects had used the same hand for feeling the stimuli and estimating size. Furthermore, use of the same hand for exploration and estimating size requires that subjects remember an extent that had been explored previously. This complicates the study of laterality by introducing memory demands to the task. It was thought that the use of a second hand for size estimates would allow subjects the option of continuing to explore a line while simultaneously making size judgments, thereby removing the problem of memory. The next experiment explicitly studied the effects of body part and movement on the illusion. 


\section{EXPERIMENT 4 Effect of Arm Versus Finger/Hand/Wrist Movement}

The purpose of this experiment was to see if differential movement strategies could explain the horizontal-vertical illusion. Conceivably, overestimation of verticals could derive from subjects' engaging in whole-arm scanning while feeling the vertical lines of larger stimuli. It seemed likely that larger patterns would induce whole-arm motion for the verticals, while smaller stimuli could be explored with motion of the finger and torsion of the wrist. This explanation was suggested by the significant effect of stimulus size in prior research, observation of subject behavior, and the dependence of the illusion on keeping one's elbow off of the table in Experiment 3. Thus, it was expected that illusory effects would be more likely with scanning derived from movement of the whole arm, a frequently used method in prior research (e.g., Day \& Avery, 1970).

Subjects in this experiment were restricted in terms of the movements they could make. They were either allowed to feel the stimuli with flexion at the wrist and hand or were forced to engage in whole-arm motion. The subjects' range of movement was controlled by foamcovered splints or restraints. Thus, some subjects had their wrists, hands, and forearms splinted. This way, they could feel patterns with the index finger only by engaging in whole-arm motions. It was hypothesized that this movement was a likely source of the previously mentioned radial-versus-tangential scanning effect. Subjects in a second group were not able to move their arms at the elbow or shoulder, and had to explore forms via hand/wrist and finger motion. If overestimation of the vertical derives from subjects using radial, whole-arm motion to feel verticals, one would expect a different pattern of results in the two conditions.

The subjects in this experiment always used their right index fingers to feel the stimuli, and the opposite hand to make size judgments. The use of the opposite hand for size estimates was adopted, since the use of a splint mandated this procedure in the whole-arm motion group. There were a couple of other reasons for restricting subjects to the use of the right hand for feeling the stimuli. The use of the right hand in right-handed subjects would probably reduce the variability associated with the use of left-handed or ambidextrous subjects. More important was a desire to avoid the practical difficulties associated with the use of restraints on the nonpreferred arm and hand. The use of splints and blocks was likely to promote clumsy exploration. We hoped to avoid excessively magnifying the motor control problems that could result from using the nonpreferred hand, especially while splinted.

\section{Method}

Subjects. The subjects were 32 (16 male, 16 female) righthanded undergraduate volunteers. Eight of each gender were assigned to whole-arm-movement $(n=16)$ and to finger/hand/wristmovement $(n=16)$ groups. The subjects were considered to be

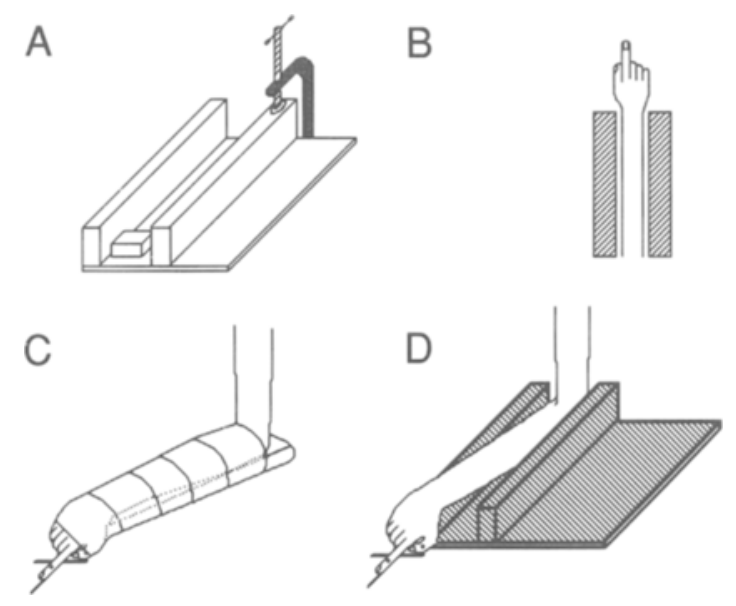

Figure 2. The splints $(C)$ and restraints used to control arm motion in Experiment 4. The foam-covered wooden blocks (A, B, D) used to restrict arm motion were made to be adjustable in order to accommodate arms of different sizes. Though not shown in $A, B$, and $D, 6-c m-h i g h \times 5-c m-$ wide $\times 20.5-\mathrm{cm}$-long blocks of firm polyfoam were glued to the top-front sections of the wooden blocks, closest to the subjects' hands.

right-handed if they responded "right hand" to all questions on the questionnaire used in Experiments 2 and 3. The subjects were blindfolded throughout the experiment.

Apparatus and Stimuli. The stimuli were the same as those used in Experiments 2 and 3. For the whole-arm-motion group, finger and wrist movements were restrained by a foam-covered, 1.8 -cm-thick wooden splint, $42 \mathrm{~cm}$ long $\times 5 \mathrm{~cm}$ wide (see Figure $2 \mathrm{C}$ ). The end, angled at $40^{\circ}$, allowed the subject's right index fingertip to protrude slightly below the bottom edge of the splint. The subject's arm was secured to the splint with an elastic support bandage $(8 \mathrm{~cm}$ wide and $200 \mathrm{~cm}$ long). The bandage was wrapped around the entire forearm, immobilizing the hand and wrist, but still allowing for movement of the elbow and shoulder (the subjects were told not to move their fingers). Thus, one group of subjects was restricted to large arm motions while feeling the stimuli.

A second group of subjects did not wear the splint, but their elbow and shoulder movements were restricted by two $6.0-\mathrm{cm}$ high $\times 37.5-\mathrm{cm}$-long blocks of wood, placed on both sides of the forearm (to the left and right of the forearm, see Figures $2 \mathrm{~A}, 2 \mathrm{~B}$, and $2 D$ ). The sides contacting the subject's forearm were covered with firm polyfoam, and a 6-cm-high block of foam was glued to the top. The wood and foam obstructed sideways elbow movement. Each subject's arm was restrained between the blocks so that he/she could feel the patterns at the body midline. The left outside edge of the left block was aligned with the center of the patterns, at the subject's body midline. The block of wood on the subject's right was held in place with a clamp, and was adjusted for the width of each subject's forearm. The subject rested the back of his or her elbow against a foam-covered block to limit arm motion. The subjects were free to rotate their hands at the wrist and to move their index fingers, but motion of the arm was restricted by the foam-covered blocks. The subjects were allowed to raise their wrists off the table surface as they scanned the stimuli with their index fingers, but lateral arm motion was controlled by the blocks. Movement of the elbow was prevented by the restraints and verbal instructions. The subjects in this finger/hand/wrist group were told to keep their elbows immobile, down on the table surface.

Design and Procedure. The experiment was a between-within, four-way design with type of movement as a between-groups factor (whole-arm or finger/hand/wrist motion) and figure, size, and 
Table 4

Effect of Arm Movement (Hand Movements vs. Large Arm Movements) as a Function of Size, Figure, and Line Orientation in Experiment 4

\begin{tabular}{|c|c|c|c|c|c|c|c|c|c|}
\hline \multirow[b]{3}{*}{ Size } & & \multicolumn{4}{|c|}{ Inverted-T Figure } & \multicolumn{4}{|c|}{ L Figure } \\
\hline & & \multicolumn{2}{|c|}{$\begin{array}{l}\text { Hand } \\
\text { Motion }\end{array}$} & \multicolumn{2}{|c|}{$\begin{array}{c}\text { Whole-Arm } \\
\text { Motion }\end{array}$} & \multicolumn{2}{|c|}{$\begin{array}{l}\text { Hand } \\
\text { Motion }\end{array}$} & \multicolumn{2}{|c|}{$\begin{array}{c}\text { Whole-Arm } \\
\text { Motion }\end{array}$} \\
\hline & & $\mathrm{H}$ & $\mathrm{V}$ & $\mathrm{H}$ & $\mathrm{V}$ & $\overline{\mathrm{H}}$ & $\mathrm{V}$ & $\mathrm{H}$ & $\mathrm{V}$ \\
\hline \multirow[t]{2}{*}{$2.5 \mathrm{~cm}$} & $M$ & 3.4 & 3.0 & 3.2 & 3.5 & 3.2 & 3.2 & 3.0 & 3.1 \\
\hline & $S D$ & 1.0 & 1.0 & .8 & 1.2 & 1.0 & 1.4 & .8 & 1.3 \\
\hline \multirow[t]{2}{*}{$5.1 \mathrm{~cm}$} & $M$ & 6.0 & 5.4 & 5.2 & 6.7 & 5.6 & 5.7 & 5.8 & 6.4 \\
\hline & $S D$ & 1.6 & 1.8 & 1.2 & 1.9 & 1.7 & 1.9 & 1.8 & 1.8 \\
\hline \multirow[t]{2}{*}{$7.6 \mathrm{~cm}$} & $M$ & 7.9 & 8.1 & 7.5 & 8.8 & 8.2 & 8.4 & 7.5 & 8.7 \\
\hline & $S D$ & 2.0 & 2.0 & 1.8 & 2.4 & 1.9 & 2.2 & 2.0 & 2.0 \\
\hline \multirow[t]{2}{*}{$10.2 \mathrm{~cm}$} & $M$ & 10.7 & 11.5 & 10.3 & 11.8 & 10.7 & 11.9 & 11.2 & 11.0 \\
\hline & $S D$ & 2.8 & 2.4 & 2.2 & 2.3 & 2.9 & 2.3 & 3.0 & 2.8 \\
\hline
\end{tabular}

Note-There were 16 subjects in the whole-arm-motion group and 16 in the finger/hand/wrist-motion group. $\mathrm{H}=$ horizontal, $\mathrm{V}=$ vertical.

line orientation as within-group factors. Sequence effects were controlled as in Experiments 1-3.

The subjects were instructed to feel both parts of the pattern with the right index finger and then make judgments about the length of each component line. Subjects reported judgments made with the left hand using a pincers posture of the thumb and index finger. The judgments were made parallel to the horizontal lines and as close to the tangible patterns as possible. It should be noted that Marchetti and Lederman (1983) reported that compatibility between the direction of an original exploratory movement and response altered the nature of judgments and the presence or absence of the tactual horizontal-vertical illusion. Illusory effects probably would have been diminished if measuring responses had been parallel to the line being judged. However, the subjects were asked to make judgments in the horizontal plane to facilitate measurement of the illusion.

If judgments had always been made parallel to the line being judged, it is possible that this could have obscured the presence of illusory effects. For example, if subjects are asked to draw a visible vertical line when given a horizontal and asked to match its size and produce an inverted $T$, they will draw the vertical as shorter, since it looks longer than it is. Similarly, when subjects were asked to do the same thing tactually with a raised-line drawing kit, they drew the vertical as shorter (unpublished research), but not as much as in vision. However, it would not be appropriate to conclude from this that the illusion is weaker in touch, since the vertical line could have felt much longer after it was drawn. Similarly, if illusory effects appear diminished when the fingers are in the same orientation as a line being judged, it is possible that subjects pulled their fingers together when they were in the vertical direction. This could happen because the illusion caused the perceived extent of their fingers to feel much greater than it actually was. The use of alternative procedures allowed for the search for converging lines of evidence on the nature of the horizontal-vertical illusion, since similar results were obtained no matter what the procedure.

\section{Results}

Table 4 shows line-length estimates for the two types of movement as a function of size, figure, and line orientation. The data of this experiment were originally analyzed using gender as a variable, but the effect of gender was nonsignificant, as were all interactions with gender (all $F$ s $<1$ ). Consequently, the data were collapsed over gender. The data were then analyzed using a 2 (movement) $\times$ 2 (figure) $\times 4$ (size) $\times 2$ (line orientation) ANOVA. The main effect of line orientation was significant $[F(1,30)=$ $16.3, p<.001]$, and the main effect of stimulus size was also highly significant $[F(3,90)=507.5, p<.001]$. A strong illusory effect was obtained $(M$ horizontal $=$ $6.83 \mathrm{~cm}, M$ vertical $=7.33 \mathrm{~cm}$ ). However, the main effect of type of movement was not significant $(F<1)$, nor was the effect of type of figure $(F<1)$.

The interaction between line orientation and type of movement was highly significant $[F(1,30)=5.89, p=.02]$. An analysis of simple effects showed that the effect of line orientation was present with large arm movements $[M$ horizontal $=6.71 \mathrm{~cm}, M$ vertical $=7.50 \mathrm{~cm}) ; F(1,15)=$ $15.01, p=.0015]$, but the effect of line orientation was nonsignificant for finger, hand and wrist motion $[M$ horizontal $=6.96 \mathrm{~cm}, M$ vertical $=7.15 \mathrm{~cm} ; F(1,15)=2.15$, $p>.15]$.

The interaction between line orientation and size was significant $[F(3,90)=3.8, p=.013]$. Illusory overestimation of verticals was greater for larger stimuli. The simple effect of line orientation was nonsignificant for the $2.5-\mathrm{cm}$ patterns $(M$ horizontal $=3.2 \mathrm{~cm}, M$ vertical $=$ $3.21 \mathrm{~cm} ; F<1$ ), marginally significant for the $5.4-\mathrm{cm}$ stimuli $[M$ horizontal $=5.66 \mathrm{~cm}, M$ vertical $=6.02 \mathrm{~cm}$; $F(1,30)=3.8, p=.061]$, but significant for the $7.5-\mathrm{cm}$ stimuli $[M$ horizontal $=7.77 \mathrm{~cm}, M$ vertical $=8.51 \mathrm{~cm}$; $F(1,30)=20.05, p<.001]$ and the $10.2-\mathrm{cm}$ stimuli $[M$ horizonta $]=10.71 \mathrm{~cm}, M$ vertical $=11.56 \mathrm{~cm}$; $F(1,30)=7.5, p=.01]$.

There was also a significant triple interaction between line orientation, size, and type of movement $[F(3,90)=3.1$, $p=.031]$. The effect of line orientation did not involve much overestimation of verticals for the $2.5-\mathrm{cm}$ stimuli, even with whole-arm motion ( $M$ horizontal $=3.01 \mathrm{~cm}$, $M$ vertical $=3.30 \mathrm{~cm}$ ). However, with whole-arm motion, the 5.4-cm patterns produced greater overestimation of verticals $(M=6.54 \mathrm{~cm})$ as compared with horizontals $(M=5.53 \mathrm{~cm})$, as did the $7.5-\mathrm{cm}$ stimuli $(M$ horizontal $=$ $7.51 \mathrm{~cm}, M$ vertical $=8.73 \mathrm{~cm}$ ) and the $10.2-\mathrm{cm}$ stimuli $(M$ horizontal $=10.71 \mathrm{~cm}, M$ vertical $=11.41 \mathrm{~cm})$.

The simple effect of line orientation for finger/hand/ wrist motion was significant for $10.2-\mathrm{cm}$ stimuli $[M$ horizontal $=10.72 \mathrm{~cm}, M$ vertical $=11.71 \mathrm{~cm} ; F(1,72)=$ $13.2, p<.01]$. The line-orientation effects were eliminated for the 2.5-, 5.4-, and 7.5-cm patterns when subjects examined the stimuli solely with finger/hand/wrist motion. The simple effect of line orientation for finger/hand/wrist motion was nonsignificant for the $2.5-\mathrm{cm}$ stimuli ( $M$ horizontal $=3.30 \mathrm{~cm}, M$ vertical $=3.11 \mathrm{~cm} ; F<1)$, the 5.4 $\mathrm{cm}$ stimuli $(M$ horizontal $=5.79 \mathrm{~cm}, M$ vertical $=5.51 \mathrm{~cm}$; $F=1.09)$, and the $7.5-\mathrm{cm}$ patterns $(M$ horizontal = $8.02 \mathrm{~cm}, M$ vertical $=8.29 \mathrm{~cm} ; F<1)($ all $p s>.10$ ).

Illusory effects were magnified by whole-arm motions for the larger stimuli. However, the effect of type of motion was also dependent upon stimulus size, so that subjects had considerable difficulty in exploring the largest patterns with finger motion without whole-arm movements. This led to the illusion's reappearing in the group restricted to finger/hand motion with the largest stimuli. The subjects with smaller hands strained to explore the 
entire $10.2-\mathrm{cm}$ horizontal lines with lateral finger motion, and this may have prompted illusory overestimation of the verticals as compared with the horizontals. It is possible that an unintended effect of the blocks was to limit lateral exploration of the horizontals, and this could have been especially problematic for smaller subjects with shorter fingers. Thus, the illusory effect of line orientation for the largest stimuli could have been an artifact of the experimental physical restraints on lateral arm motion. The interaction between line orientation and figure was nonsignificant, as was the interaction between figure and type of movement (both $F_{\mathrm{s}}<1$ ).

There was a significant interaction between line orientation, figure, and type of movement $[F(1,30)=6.0, p=$ $.021]$. For the purpose of clarification of this three-way interaction between line orientation, figure, and type of movement, the simple effects of line orientation were examined for the $L$ figure and the inverted-T figure by type of movement. An analysis of simple effects indicated that the effect of line orientation was significant only when subjects felt the patterns using large arm movements for the inverted-T figure $[M$ horizontal $=6.55 \mathrm{~cm}$, $M$ vertical $=7.70 \mathrm{~cm} ; F(1,60)=24.8, p<.01]$. The effect of line orientation was marginally significant with the $\mathrm{L}$ figure $[M$ horizontal $=6.87 \mathrm{~cm}, M$ vertical $=7.30 \mathrm{~cm}$; $F(1,60)=3.3, p<.10]$. However, the effect of line orientation was marginally significant with the L figure $[M$ horizontal $=6.93 \mathrm{~cm}, M$ vertical $=7.30 \mathrm{~cm} ; F(1,60)=$ $2.5, p>.10$ ] or absent for the inverted-T figure ( $M$ horizontal $=6.98 \mathrm{~cm}, M$ vertical $=7.01 \mathrm{~cm} ; F<1$ ) when subjects used finger/hand/wrist motion. The effect of whole-arm motion was linked to type of figure, with an increase in the size estimates of the vertical segments of the inverted-T figures. That is, the illusory overestimation of verticals was greater for the larger inverted-T figures, especially with whole-arm motion.

\section{Discussion}

Experiment 4 showed that the horizontal-vertical illusion is induced by whole-arm motions, even when the right hand was used to explore the stimuli. Recall that in Experiment 2, use of the left hand increased the horizontalvertical illusion. These whole-arm motions are likely to prompt illusory overestimation of verticals with respect to horizontals when the motions are radial. Smaller movements of the finger do not generate illusory effects, and this is consistent with the lack of illusory overestimation when smaller stimuli were explored under normal, unconstrained conditions.

It is possible, of course, that the results of Experiment 4 may be explicable in terms of posture and arm elevation and not movement strategy. That is, perhaps illusory effects were a consequence of raising one's elbow off of the table and not of radial arm motion. This explanation of the data is suggested by the results of Experiment 3.

To rule out this postural explanation of the horizontalvertical illusion, an additional control group $(n=16 ; 8$ males and 8 females) explored the raised line drawings of $L$ and inverted-T figures of Experiment 4, using whole- arm movement. The right-handed subjects all wore the splint that eliminated any hand or finger motion during tactual exploration. In addition, they were required to keep their elbows on the table surface while feeling the patterns with the index finger of the right hand. The subjects were told to slide their bandaged, splinted arms on the table surface as they used their index fingers to feel the stimuli; they were prevented from making any lateral finger motions. As in Experiment 4, size judgments were made with the left hand, parallel to the the horizontal line, at the body midline.

The horizontal-vertical illusion was obtained, since the effect of line orientation $(M$ horizontal $=7.11 \mathrm{~cm}$, $M$ vertical $=8.12 \mathrm{~cm})$ was highly significant $[F(1,15)=$ $36.3, p<.001]$, as was the effect of stimulus size $[F(3,45)=171.7, p<.001]$. While the effect of figure $(M \mathrm{~L}=7.80 \mathrm{~cm}, M \mathrm{~T}=7.47 \mathrm{~cm})$ was nonsignificant $[F(1,15)=1.4, p>.25]$, the interaction between figure and line orientation was highly significant $[F(1,15)=$ $10.3, p<.01]$. This reflected stronger effects of line orientation for the inverted T $(M$ horizontal $=6.80 \mathrm{~cm}$, $M$ vertical $=8.13 \mathrm{~cm})$ than for the L figure $(M$ horizontal $=7.43 \mathrm{~cm}, M$ vertical $=8.18 \mathrm{~cm})$. However, analyses of simple effects showed that line orientation was significant for the $\mathrm{L}$ figure $[F(1,15)=11.1, p=.005]$ and for the inverted $\mathrm{T}[F(1,15)=69.1, p<.001]$. Thus, the illusion was obtained for both types of figures. All of the other interactions were nonsignificant (all $p s>.05$ ). This means that the horizontal-vertical illusion derived from whole-arm motion and not from an awkward posture or elevation of the arm.

\section{GENERAL DISCUSSION}

The present experiments showed that the tactual horizontal-vertical illusion is very much dependent upon the nature of the scanning strategies chosen by subjects. Experiment 1 showed that the illusion occurs with both continuous and bisected lines. This means that the the illusion is not simply explicable in terms of bisection. As in earlier reports, the illusory effects were often found with the inverted-T figure, or were stronger for that configuration in Experiments 2-4. The illusory effects in all of the experiments were generally greater for the larger stimuli, and this suggested the importance of the subjects' choice of scanning methods. Experiment 3 was consistent with a whole-arm-motion interpretation of the illusion, since raising one's elbow off the table surface induced overestimation of verticals with respect to horizontals. Experiment 4 provided support for this wholearm-movement interpretation of the data, since the illusion disappeared or was weakened when subjects were prevented from moving their arms. Furthermore, the illusion was obtained when subjects kept their splinted arms on the table surface and engaged in radial, sliding arm motions. Thus, whole-arm scanning hurt performance and yielded illusory overestimation of verticals.

The results of the experiments are relevant to theoretical points of view that assume intersensory equivalence. 
On the assumption that form is a primary quality of an object, one might assume that similar perceptual phenomena should occur in both vision and touch. The absence of the illusion for smaller stimulus configurations means that it may not be appropriate to engage in blanket generalizations from visual to tactual phenomena. Moreover, circumstances surrounding tactual exploration are important, and the presence of different explanatory mechanisms make one wonder if it makes sense to think of the hand as just a "clumsy eye." The presence of the tactual illusion was dependent upon keeping the subjects' arms off of the table surface and/or the use of whole-arm motions.

The present experiments show the importance of scale for tactual perception. When stimuli are small enough, touch may not be subject to illusory effects. Illusory effects are diminished as stimuli decrease in size, and may be minimal as their size is reduced to well below that of the span of the fingers of one hand. This is consistent with the data showing an absence of the illusion for the smaller stimuli. Thus, larger patterns prompt different sorts of exploratory behaviors than do smaller stimuli. Subjects are likely to use whole-arm motions when feeling larger stimuli, and touch is then susceptible to radial versus tangential scanning effects and the consequent illusion. This interpretation is supported by the results of Experiments 3 and 4.

The present results are consistent with a recent theoretical position presented by Paillard (1991). Paillard has argued that we need to understand touch in terms of the body schema, and a number of sensorimotor and representational spaces. It matters whether we look at something with our eyes using foveal or peripheral vision. Similarly, Paillard has proposed that, for touch, it is significant whether we think of action spaces such as a "reach space" or a representational space that operates within a "hand space." Paillard distinguished between a "location" space and a "shape" space for touch. From this theoretical viewpoint, it is important whether we try to examine patterns with our fingers (shape space) or with our arms, or whether we attempt locomotion in the world. The data from one set of limited task demands may not generalize directly to the other. Palpation of an object is centered on understanding of the object, while hand placement with respect to the body is very different, and is related to a body-centered coordinate system (Paillard, 1991, p. 168). The present data are consistent with this perspective, and show that perceptual distortion is less likely within the "hand space." Katz viewed the hand as the organ of touch, and even pointed out that fingers are superior to the eye in making judgments of the thickness of paper (see Katz, 1989, p. 3). ${ }^{1}$

It should be noted that the results of the present set of experiments are also consistent with a large literature on perception in blind people. Blind people, whether congenitally or late blind, may show better performance than sighted individuals when considering small shapes or braille (see Heller, 1993), but deficiencies in congen- itally blind people may appear sporadically in tasks involving orientation in large-scale space. In addition, the data are also consistent with an earlier report by Martinez (1971), who studied the ability of children to discriminate mirror images with vision or with touch. Martinez found that tactual pattern perception was impaired when blindfolded children were limited to movement of the arm and shoulders by a splint. Furthermore, the performance of the children using touch was comparable to visual performance but only when the blindfolded subjects were allowed to explore patterns using only finger and wrist motion.

Task demands may force the coordination of spatial knowledge and require subjects to interrelate spatial schemes. Thus, the tactual identification of some small geometric patterns may be possible using spatial frames of reference that are entirely egocentric. There are stimuli that are orientation specific, such as braille or embossed letters. If task demands require mental rotation for these sorts of stimuli, subjects need to relate spatial frames of reference and a body-centered coordinate systems to the tangible array (Heller, 1993). When this is not possible, pattern identification suffers. For example, braille identification is hindered when sighted subjects are unable to see their hands as they touch embossed braille patterns. Performance improves when the subjects are permitted visual guidance. However, the benefits of visual guidance are dependent upon allowing subjects sight of the angle of their fingers touching braille and the angle of the line of braille (Heller, 1989). The assistance of visual guidance was not found when subjects viewed a single light-emitting diode on their fingertips and stained glass was used to render the embossing invisible. The benefits of visual guidance in these experiments suggest that orientation-specific patterns and task demands may promote attention to spatial reference schemes involving knowledge of one's body orientation, the orientation of patterns in space, and abstract schemes involving knowledge of the horizontal and the vertical (Heller, 1993).

Note that the present results are also consistent with the views of Barber and Lederman (1988), who argued for a fundamental difference between manipulatory and ambulatory space. However, their distinction described a space that could be reached with whole-arm motions, and they contrasted this with a much larger space that required motion of the entire body. The present results suggest that a further distinction is needed, that is, between a "hand" space that can be examined without arm motion and the larger, manipulatory space that prompts motion of the whole arm.

Perhaps differences in scanning-rate may be the underlying variable that could explain the obtained relationship between stimulus size and movement type. Wong's (1977) scanning-rate hypothesis proposed that radial scanning was executed more slowly than tangential scanning, and that this might explain the difference in judgments of extent for horizontal and vertical lines. This is only part of the story, however, since scanning effects are 
clearly dependent upon whole-arm movements. In the present experiments, we did not attempt to verify the scanning-rate explanation, but the results are certainly consistent with it. Furthermore, it is possible that the illusory effects might derive from other mechanisms that remained uncontrolled in the present experiments. Thus, whole-arm motion in Experiment 4 forced subjects to engage in scanning with bent elbows. In this case, the upper arm and forearm moved in different directions. This articular angular difference did not occur when subjects used tangential motion, and it is possible that this could explain the radial versus tangential scanning effects. Radial whole-arm motion requires greater effort (given flexion at the elbow) than tangential arm motion, where the upper arm and forearm move in consistent directions. It may simply be more difficult to engage in arm motions involving flexion at the elbow. Wong (1977) also claimed that radial motions have more resistance to inertia than do tangential motions. However, Marchetti and Lederman (1983) were unable to verify this hypothesis. Further research will be needed to verify the relevance of such a possible mechanism.

Possibly, whole-arm motion is merely clumsy and imprecise, and this may prompt illusions in touch. This motor-control explanation of the tactual illusion is consistent with the results of Experiment 2 in showing a relationship between the use of the left hand and the overestimation of verticals. It was suggested that it might be more difficult to control scanning rate with the left hand, and this may provide a mechanism worth investigating in future research.

In addition, the presence of gender differences complicates the issue, since that factor interacted with figure and hemispace in Experiment 2. Males treated the figures alike in the left hemispace but judged the inverted-T figures as smaller than the Ls at the midline and in the right hemispace. Future research in this area should consider the possible impact of these variables. However, the effects of gender and hemispace were small in magnitude, and may not be readily explainable in terms of cerebral lateralization. Gender and body size are essentially confounded, and body size may be the relevant variable. The presence of the illusion was not linked to involvement of the left hemisphere of the brain, and the small effects of gender that were found are consistent with other reports of unreliable effects of gender and hand in dichaptic experiments (see Summers \& Lederman, 1990). Note that illusory effects were obtained in Experiment 4, despite the use of the right hand. Furthermore, the effect of hand was nonsignificant in Experiment 1.

The present results are relevant to the development of graphics for blind people. Visual experience can alter tactual perception of raised line drawings (Heller et al., 1996; Heller \& Joyner, 1993; Heller, Kennedy, \& Joyner, 1995). It may be important to consider scale when producing tangible displays. Smaller configurations may not show the same sort of perceptual effects as larger graphical arrays. Moreover, it is not known if spatial distortion will appear in other, unexpected ways as display size is increased.

\section{REFERENCES}

Balakrishnan, J. D., Klatzky, R. L., LoOmis, J. M., \& Lederman, S. J. (1989). Length distortion of temporally extended visual displays: Similarity to haptic spatial perception. Perception \& Psychophysics, 46, 387-394.

Barber, P. O., \& Lederman, S. J. (1988, March). Encoding direction in manipulatory space and the role of visual experience. Journal of Visual Impairment \& Blindness, 82, 99-105.

BEAN, C. H. (1938). The blind have "optical illusions." Journal of Experimental Psychology, 22, 283-289.

Bradshaw, J. L., Burden, V., \& Nettleton, N. C. (1986). Dichotic and dichaptic techniques. Neuropsychologia, 24, 79-90.

Bradshaw, J. L., NetTleton, N. C., \& Spehr, K. (1982). Braille reading in the left and right hemispace. Neuropsychologia, 20, 493-500.

Bryden, M. P., \& SteEnhuis, R. E. (1991). Issues in the assessment of handedness. In F. L. Kitterle (Ed.), Cerebral laterality: Theory and research (pp. 35-51). Hillsdale, NJ: Erlbaum.

Chan, T., Carello, C., \& Turvey, M. T. (1990). Perceiving object width by grasping. Ecological Psychology, 2, 1-35.

Coren, S., \& Girgus, J. S. (1978). Seeing is deceiving: The psychology of visual illusions. Hillsdale, $\mathrm{NJ}$ : Erlbaum.

DAvIDSON, P. W. (1972). Haptic judgments of curvature by blind and sighted humans. Journal of Experimental Psychology, 93, 43-55.

DAY, R. H., \& AVERY, G. C. (1970). Absence of the horizontal-vertical illusion in haptic space. Journal of Experimental Psychology, 83, 172-173.

DAY, R. H., \& WONG, T. S. (1971), Radial and tangential movement directions as determinants of the haptic illusion in an L figure. Journal of Experimental Psychology, 87, 19-22.

Gibson, J. J. (1966). The senses considered as perceptual systems. Boston: Houghton Mifflin.

GoodNow, J. J. (1969). Eye and hand: Differential sampling of form and orientation properties. Neuropsychologia, 7, 345-373.

Hatwell, Y. (1960). Étude de quelques illusions géométriques tactiles chez les aveugles [Study of some tactile geometric illusions in the blind]. L'Année Psychologique, 60,11-27.

HeElan, P. A. (1988). Space-perception and the philosophy of science. Berkeley: University of California Press.

Heller, M. A. (1989). Tactile memory in sighted and blind observers: The influence of orientation and rate of presentation. Perception, 18, $121-133$.

Heller, M. A. (1992). The effect of orientation on tactual braille recognition: Optimal touching positions. Perception \& Psychophysics, 51, 549-556.

Heller, M. A. (1993). Influence of visual guidance on braille recognition: Low lighting also helps touch. Perception \& Psychophysics, 54, 675-681

Heller, M. A., Calcaterra, J. A., Tyler, L. A., \& Burson, L. L. (1996). Production and interpretation of perspective drawings by blind and sighted people. Perception, 25, $321-334$.

Heller, M. A., \& Joyner, T. D. (1993). Mechanisms in the tactile horizontal-vertical illusion: Evidence from sighted and blind subjects. Perception \& Psychophysics, 53, 422-428.

Heller, M. A., Joyner, T. D., \& DAN-Fodio, H. (1993). Laterality effects in the haptic horizontal-vertical illusion. Bulletin of the Psychonomic Society, 31, 440-442.

Heller, M. A., Kennedy, J. M., \& Joyner, T. D. (1995). Production and interpretation of pictures of houses by blind people. Perception, 24, 1049-1058.

ItTELSON, W. H. (1996). Visual perception of markings. Psychonomic Bulletin \& Review, 3, 171-187.

KATZ, D. (1989). The world of touch (L. E. Krueger, Ed. \& Trans.). Hillsdale, NJ: Erlbaum.

KünNAPAS, T. M. (1955). An analysis of the "vertical-horizontal illusion." Journal of Experimental Psychology, 49, 134-140.

MarchetTi, F. M.; \& Lederman, S. J. (1983). The haptic radial- 
tangential effect: Two tests of Wong's "moments-of-inertia" hypothesis. Bulletin of the Psychonomic Society, 21, 43-46.

Martinez, F. (1971). Comparison of two types of tactile exploration in a task of mirror-image recognition. Psychonomic Science, 22, 124-125.

MCKEEVER, W. F. (1991). Handedness, language, laterality and spatial ability. In F. L. Kitterle (Ed.), Cerebral laterality: Theory and research (pp. 53-70). Hillsdale, NJ: Erlbaum.

Millar, S. (1984). Is there a "best hand" for braille? Cortex, 20, 75-87.

O'NeIL, W. M. (1958). Basic issues in perceptual theory. Psychological Review, 65, 348-361.

Paillard, J. (1991). Motor and representational space. In J. Paillard (Ed.), Brain and space (pp. 163-182). New York: Oxford University Press.

Revesz, G. (1950). The psychology and art of the blind. London: Longmans Green.

Summers, D. C., \& Lederman, S. J. (1990). Perceptual asymmetries in the somatosensory system: A dichaptic experiment and critical review of the literature from 1929 to 1986. Cortex, 26, 201-226.

TEDFORD, W. H., JR., \& TUDOR, L. L. (1969). Tactual and visual illusions in the T-shaped figure. Journal of Experimental Psychology, 81, 199-201.
VAN DOREN, C. L. (1995). Cross-modality matches of finger span and line length. Perception \& Psychophysics, 57, 555-568.

Wong, T. S. (1977). Dynamic properties of radial and tangential movements as determinants of the haptic horizontal-vertical illusion with an L figure. Journal of Experimental Psychology: Human Perception \& Performance, 3, 151-164.

\section{NOTE}

1. Heelan (1988) argued that visual space is often non-Euclidean, and curved. The curvature of space depends upon scale and experience, according to Heelan. Informal observation suggests that haptics could be subject to similar distortion, at least for some subjects. A number of subjects were asked to draw the forms they had previously felt after the end of a pilot experiment. A couple of them drew the horizontal segment of the inverted-T or the $\mathrm{L}$ figure as curved. Underestimation of the horizontal could derive from this distortion, at least for some individuals. Haptic perceptual skill probably helps to promote judgments in Euclidean space.

(Manuscript recieved September 25, 1995; revision accepted for publication January $6,1997$. 